\title{
Microwave Assisted Synthesis, Characterization and Biological Study of Some Chalcone Compounds Derived from Phenyl Isothiocyanate
}

\author{
Suha K. Al-Mosawi ${ }^{1} \quad$ Hanan A. Al-Hazam ${ }^{2} \quad$ Abbas F. Abbas ${ }^{2}$ \\ 1.Department of pharmaceutical chemistry, College of Pharmacy, University of Basrah, Basrah-Iraq \\ 2.Department of Chemistry, College of Science, University of Basrah, Basrah-Iraq
}

\begin{abstract}
Chalcones are synthesized by Claisen-Schmidt condensation, which involves cross-aldol condensation of appropriate aldehydes and ketones by base catalyzed reaction, the new chalcone derivatives synthesized by the reaction aldehyde with their compounds. By microwave assisted synthesis, a considerable increase in the reaction rate has been observed and that too, with better yields. M.P., TLC, CHN, FTIR, NMR and MS spectroscopy has characterized all the synthesized compounds. The biological screening data of the synthesized compounds were also studied.
\end{abstract}

Keywords: microwave, chalcone, antibacterial.

DOI: $10.7176 / \mathrm{CMR} / 11-3-05$

Publication date:March $31^{\text {st }} 2019$

\section{Introduction}

Microwave dielectric heating uses the ability of some liquids and solids to transform electromagnetic radiation into heat to drive chemical reactions. The entry of microwave ovens possible to carry out many transformations with greater efficiency and ease of workup [Hoz et al, 2005, Gedye et al,1998, Nuchter et al,2000] the use of microwave has becomes very attractive in the field of medical sciences [Chattree et al, 2013]. Microwave-induced organic reaction enhancement (MORE) chemistry [Syam et al, 2012 and Modzelewska et al, 2006] is gaining popularity as a non-conventional technique for rapid organic synthesis. Important features of this technique are easy access to very high temperature, good control over energy input in a reaction, higher yields and rapid synthesis of organic compounds.

Chalcones are 1,3-diphenyl-urea derivatives in which three aromatic rings are linked by a three carbon $\alpha, \beta$ unsaturated carbonyl system. These are abundant in edible plants and are considered to be the precursors of flavonoids and isoflavonoids [Hassan et al, 2007]. Chalcones are synthesized by Claisen-Schmidt condensation, which involves cross-aldol condensation of appropriate aldehydes and ketones by base catalyzed or acid catalyzed reaction followed by dehydration. Chalcone is a common natural pigment and one of the important intermediate in the biosynthesis of flavonoids. Synthetic and naturally occurring chalcones have been extensively studied and developed as one of the pharmaceutically important molecules. Chalcone derivatives are screened for their antiinflammatory activity [Herenciaa et al, 1998], chemo preventive activity [Ahmad et al, 2016], cardiovascular disease [Tiellas,etal,2016], anticancer activity[Das et al, 2016], cytotoxic activity [Kothalet al, 2017], antiprolifirative activity [Mellado, et al, 2018], antimalarial activity [Yadav et al, 2012], antiviral activity [Gan et al, 2017] and anti-HIV activity [Al-Hazam et al, 2017]. Therefore, in the present investigation, it has been considered worthwhile to synthesize some new chalcone derivatives by conventional and microwave irradiation methods and a comparison has been made between two methods.

\section{Experimental Work}

Melting point were determined in Buchi thermal point apparatus and were uncorrected, Elemental analysis $(\mathrm{CHN})$ were recorded in Costech ESC4010 CHNSO in University of Tehran in Iran. FT-IR Spectra were recorded on Shimadzu FT-IR 8400 Fourier Transformer infrared as KBr disk in the range $40-4000 \mathrm{~cm}^{-1} .{ }^{1} \mathrm{HNMR}$ and ${ }^{13} \mathrm{CNMR}$ spectra were recorded on Brucker spctrospin ultra shield magnets $400 \mathrm{MHz}$ instrument using tetramethyl silane (TMS) as an internal standard and DMSO- $\mathrm{d}_{6}$ as a solvent in university of university of Tehran. The compounds were synthesized by microwave type Panasonic microwave instrument (Malaysia), NN-SN382, compact 20L, power1200 Watt and frequency $2450 \mathrm{MHz}$, by using turntable system with different powers between 90-300W. Thin layer chromatography were performed on pre-coated sheets with $0.25 \mathrm{~mm}$ layer of Silica Gel GF254 of the Merck Company.

\section{Synthesis of Compounds}

1- Synthesis 1-(4-Acetylphenyl)-3-phenylthiourea

A mixture of 4 -aminoacetophenone $(1.4 \mathrm{gm}, 0.01 \mathrm{~mole})$ and phenyl thiocyanate $(1.35 \mathrm{gm}, 0.01 \mathrm{~mol})$ in $50 \mathrm{ml}$ dry acetone, then irradiated inside microwave oven $270 \mathrm{~W}$ for $4 \mathrm{~min}$. The reaction was monitored by TLC using eluent 
n-hexane: ethyl acetate (3:7), the obtained product white crystals was filter off and recrystallized from ethanol to give 1-(4-Acetylphenyl)-3-phenylthiourea (m.p. $160-162^{\circ} \mathrm{C}$ ).

\section{2- Synthesis of Chalcone (a-h)}

A mixture of $(0.27 \mathrm{gm}, 0.01$ mole $)$ of 1-(4-Acetylphenyl)-3-phenylthiourea, (0.01mole) of substituted benzaldehydes were dissolved in $3 \mathrm{ml}$ of ethanol and $1 \mathrm{ml}(40 \%) \mathrm{KOH}$ then irradiated inside microwave oven $90 \mathrm{~W}$ for $4 \mathrm{~min}$. The reaction was monitored by TLC using eluent n-hexane: ethyl acetate (3:7), then it was poured in to crushed ice and acidified with $\mathrm{HCl}$. The solid separated was filtered and recrystallized from ethanol.

(a): yield $83 \%$. Melting point $200-202^{\circ} \mathrm{C}, \mathrm{CHN}$ analysis that formula $\mathbf{C}_{22} \mathbf{H}_{17} \mathbf{B r N}_{2} \mathbf{O S}$ calculated C, $60.422 \mathrm{H}$, 3.925 N, 3.925 S, 7.335; Found C, 60.366 H, 3.884 N, 6.385, S, 7.258. FT-IR spectra vmax 3224, 3012, 1678, $1546,1338,698 \mathrm{~cm}^{-1} .{ }^{1} \mathrm{HNMR}$ spectra $\delta \mathrm{ppm},(9.89,1 \mathrm{H}) \mathrm{s},(9.61,1 \mathrm{H}) \mathrm{s}(6.51,1 \mathrm{H}) \mathrm{s}$ and $(6.00,3 \mathrm{H})$ t. ${ }^{13} \mathrm{CNMR}$ spectra $\delta$ ppm, 93.5, 121.7, 126.7, 128.1, 134.9, 135.3, 131.3, 128.1 128.2, 128.8, 128.5, 180.5, 161.3, 130.6, 131.3 and 134.9. MS spectra (m/z),436, 228, 211, 135,138, 157,93,77and51

(b): yield $80 \%$. Melting point $160-162^{\circ} \mathrm{C}, \mathrm{CHN}$ analysis that formula $\mathbf{C}_{23} \mathbf{H}_{20} \mathbf{N}_{2} \mathbf{O S}$ calculated C, $74.160 \mathrm{H}, 5.413$ N, 7.522 S, 8.611; Found C, 74.100 H, 5.389 N, 7.447, S, 8.521. FT-IR spectra vmax 3375, 3018, 2978, 1730 , $1683,1595 \mathrm{~cm}^{-1}$. ${ }^{1} \mathrm{HNMR}$ spectra $\delta \mathrm{ppm},(9.63,1 \mathrm{H}) \mathrm{s},(9.38,1 \mathrm{H}) \mathrm{s}(6.51,1 \mathrm{H}) \mathrm{s},(6.00,3 \mathrm{H}) \mathrm{t}$ and $(2.2,3 \mathrm{H}) .{ }^{13} \mathrm{CNMR}$ spectra $\delta$ ppm, 99.6, 110.6, 121.7, 136.3, 135.4, 141.7, 163,9, 126.8, 127.5, 127.8, 160.0, 174.3, 163.9, 128.7, 128.8, 132.4 and 23.2. . MS spectra (m/z),372, 288, 146, 135, 118, 92, 93, 77 and 51

(c): yield $85 \%$. Melting point $179-181^{\circ} \mathrm{C}$, CHN analysis that formula $\mathbf{C}_{22} \mathbf{H}_{17} \mathbf{C l N}_{2} \mathbf{O S}$ calculated C, $67.259 \mathrm{H}, 4.366$ N, 7.133 S, 8.186; Found C, 67.212 H, 4.228 N, 7.088 S, 8.004. FT-IR spectra vmax 3215, 3028, 2916, 1658, $1600,1330,813 \mathrm{~cm}^{-1} .{ }^{1} \mathrm{HNMR}$ spectra $\delta \mathrm{ppm},(9.69,1 \mathrm{H}) \mathrm{s},(9.31,1 \mathrm{H}) \mathrm{s}(7.71,1 \mathrm{H}) \mathrm{s}$ and $(4.94,3 \mathrm{H}) \mathrm{t} .{ }^{13} \mathrm{CNMR}$ spectra

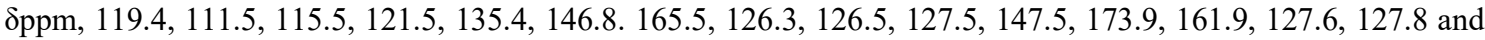
133.7. . MS spectra (m/z), 392, 228, 166, 135, 138, 112, 93, 77 and 51.

(d): yield $84 \%$. Melting point $180-182^{\circ} \mathrm{C}, \mathrm{CHN}$ analysis that formula $\mathbf{C}_{22} \mathbf{H}_{17} \mathbf{F N}_{2} \mathbf{O S}$ calculated C, $70.196 \mathrm{H}, 4.552$ N, 7.448, S, 8.528; Found C, 70.012 H, 4.465 N, 7.333 S, 8.449. FT-IR spectra vmax 3272, 2962, 1631, 1257, 825 $\mathrm{cm}^{-1} .{ }^{1} \mathrm{HNMR}$ spectra $\delta \mathrm{ppm},(9.72,1 \mathrm{H}) \mathrm{s},(9.04,1 \mathrm{H}) \mathrm{s}(7.17,1 \mathrm{H}) \mathrm{s}$ and $(4.95,3 \mathrm{H}) \mathrm{t} .{ }^{13} \mathrm{CNMR}$ spectra $8 \mathrm{ppm}, 99.5$, $110.9,15.3,115.5,129.9,135.4,162.9,121.7,126.3,126.7,139.1,174,2,152.5,127.5,127.8$, and 128.9. . MS spectra $(\mathrm{m} / \mathrm{z}), 376,228,150,135,122,96,93,77$ and 51.

(e): yield $78 \%$. Melting point $176-178^{\circ} \mathrm{C}$, CHN analysis that formula $\mathbf{C}_{22} \mathbf{H}_{16} \mathbf{N}_{2} \mathbf{O S}$ calculated C, $73.723 \mathrm{H}, 5.068$ N, 7.822 S, 8.948; Found C, 73.623 H, 4.886 N, 7.695 S, 8.747.. FT-IR spectra vmax 3240, 3055, 1643, 1573 , $1319 \mathrm{~cm}^{-1} .{ }^{1} \mathrm{HNMR}$ spectra $\delta \mathrm{ppm},(9.79,1 \mathrm{H}) \mathrm{s},(9.41,1 \mathrm{H}) \mathrm{s}(6.42,1 \mathrm{H}) \mathrm{s}$ and $(6.00,3 \mathrm{H}) \mathrm{t} .{ }^{13} \mathrm{CNMR}$ spectra $\delta \mathrm{ppm}, 98.4$, $111.1,121.6,126.2,135.3,142.8,137.7,126.6,126.9,127.5,161.5,180.2,165.5,127.7,127.8$ and 128.6. . MS spectra $(\mathrm{m} / \mathrm{z}), 358,228,132,135,104,93,77$ and 51 .

(f): yield $80 \%$. Melting point $146-148^{\circ} \mathrm{C}, \mathrm{CHN}$ analysis that formula $\mathbf{C}_{24} \mathbf{H}_{23} \mathbf{N}_{3} \mathbf{O S}$ calculated C, $71.795 \mathrm{H}, 5.778$ N, 10.475 S, 7.985; Found C, 71.722 H, 5.622 N, 10.255, S, 7.895. FT-IR spectra vmax 3331, 3053, 2924, 1681, $1527.1315 \mathrm{~cm}^{-1}$. ${ }^{1} \mathrm{HNMR}$ spectra $\delta \mathrm{ppm},(9.54,1 \mathrm{H}) \mathrm{s},(9.28,1 \mathrm{H}) \mathrm{s}(6.42,1 \mathrm{H}) \mathrm{s},(6.00,3 \mathrm{H}) \mathrm{t}$ and $(3.64,3 \mathrm{H}){ }^{13} \mathrm{CNMR}$ spectra $\delta$ ppm, 97.6, 110.1, 111.5, 121.4, 133.5, 137.0, 138.2, 126.7, 128.1, 128.5, 135.5, 131.6, 137.5, 127.7, 128.9, 131.4 and 61.8. MS spectra (m/z), 401, 228, 175, 135, 147, 121, 93, 77 and 51.

(g): yield $88 \%$. Melting point $228-230^{\circ} \mathrm{C}, \mathrm{CHN}$ analysis that formula $\mathbf{C}_{22} \mathbf{H}_{17} \mathbf{N}_{3} \mathbf{O}_{3} \mathbf{S}$ calculated C, $65.495 \mathrm{H}, 4.254$ N, 10.422 S, 7.956; Found C, 65.344 H, 4.005 N, 10.235, S, 7.775. FT-IR spectra vmax 3340, 2926, 1674, 1600, $1346 \mathrm{~cm}^{-1} .{ }^{1} \mathrm{HNMR}$ spectra $\delta \mathrm{ppm},(9.53,1 \mathrm{H}) \mathrm{s},(9.21,1 \mathrm{H}) \mathrm{s}(6.84,1 \mathrm{H}) \mathrm{s}$ and $(6.4,3 \mathrm{H}) \mathrm{t} . .^{13} \mathrm{CNMR}$ spectra $\delta p p m, 40,45$, $53,87,117,118,120,123,127,128,129,135,138,141,144,148,158,161,171,174,177,181$. MS spectra (m/z), $403,228,177,135,149,123,93,77$ and 51.

(h): yield $79 \%$. Melting point $155-157^{\circ} \mathrm{C}, \mathrm{CHN}$ analysis that formula $\mathbf{C}_{23} \mathbf{H}_{\mathbf{2 0}} \mathbf{N}_{\mathbf{2}} \mathbf{O}_{2} \mathbf{S}$ calculated C, $71.114 \mathrm{H}, 5.195$ N, 7.213 S, 8.254; Found C, 70.865H, 5.004 N, 7.119 S, 8.154. FT-IR spectra vmax 3361, 3061, 1681, 1599, 1267 $\mathrm{cm}^{-1} .{ }^{1} \mathrm{HNMR}$ spectra $\delta \mathrm{ppm},(9.61,1 \mathrm{H}) \mathrm{s},(9.05,1 \mathrm{H}) \mathrm{s}(6.92,1 \mathrm{H}) \mathrm{s}$ and $(4.86,3 \mathrm{H}) \mathrm{t}$ and $(3.74,3 \mathrm{H}) .{ }^{13} \mathrm{CNMR}$ spectra

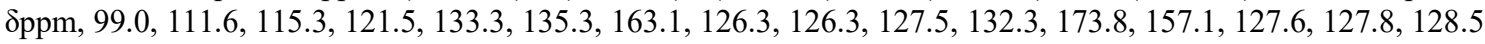
and 55.1. MS spectra (m/z), 388, 228, 162, 1354, 134, 108, 93, 77 and51.

(i): yield $75 \%$. Melting point $216-218^{\circ} \mathrm{C}$, CHN analysis that formula $\mathbf{C}_{22} \mathbf{H}_{18} \mathbf{N}_{2} \mathbf{O}_{2} \mathbf{S}$ calculated C, $70.575 \mathrm{H}, 4.854$ N, 7.485 S, 8.567; Found C, 70.325 H, 4.625 N, 7.309 S, 8.493. FT-IR spectra vmax 3417, 3240, 1643, 1615, $1597,1230 \mathrm{~cm}^{-1} .{ }^{1} \mathrm{HNMR}$ spectra $\delta \mathrm{ppm},(9.62,1 \mathrm{H}) \mathrm{s},(9.47,1 \mathrm{H}) \mathrm{s},(8.93,1 \mathrm{H}) \mathrm{s}(6.74,1 \mathrm{H}) \mathrm{s}$ and $(4.82,3 \mathrm{H}) \mathrm{t.}{ }^{13} \mathrm{CNMR}$ spectra $\delta$ ppm, 99.1, 119.5, 121.2, 126.7, 134.9, 135.5, 148.6, 126.9, 128.1, 128.5, 138.6, 131.1, 147.9, 128.8, 131.1 and 131.5. MS spectra (m/z), 374, 228, 148, 135, 120, 92, 93, 77 and 51 .

(j): yield $70 \%$. Melting point $178-180^{\circ} \mathrm{C}$, CHN analysis that formula $\mathbf{C}_{23} \mathbf{H}_{20} \mathbf{N}_{2} \mathbf{O}_{3} \mathbf{S}$ calculated C, $68.302 \mathrm{H}, 4.985$ N, 6.935 S, 7.933; Found C, 68.025 H, 4.863 N, 6.778 S, 7.798. FT-IR spectra vmax 3488, 3329, 3053, 3100, $1658,1597,1342 \mathrm{~cm}^{-1} .{ }^{1} \mathrm{HNMR}$ spectra $\delta \mathrm{ppm},(9.65,1 \mathrm{H}) \mathrm{s},(8.97,1 \mathrm{H}) \mathrm{s},(7.67,1 \mathrm{H}) \mathrm{s}(6.82,1 \mathrm{H}) \mathrm{s},(4.88,3 \mathrm{H}) \mathrm{t}$ and $(3.76,3 \mathrm{H}) \mathrm{s} .{ }^{13} \mathrm{CNMR}$ spectra $\delta \mathrm{ppm}, 111.0,111.3,111.9,119.0,135.2,135.4,131.7,121.6,126.3,126.6,148.3$, 174.0, 148.7, 127.5, 127.7, 127.7 and 58.1. MS spectra (m/z), 404, 228, 178, 135, 150, 124, 108, 93, 77 and 51. 


\section{RESULT AND DISCUSSION}

Chalcone derivatives form a group of generally less investigated compounds. However, recently growing efforts are made to synthesize and characterized these compounds. Many chalcone derivatives possess very promising properties regarding biological activities as shown in literature survey. In the present research, project the conventional methods to prepare some chalcones compounds with expected biological activity.

The Purification of 1-(4-Acetylphenyl)-3-phenylthiourea compound was tested first by thin layer chromatography (TLC) using different eluents. The best separation was obtained in mixture of (n-hexane: ethyl acetate) having ratio (3:7) respectively as eluent. Then, the product was purified by absolute ethanol.

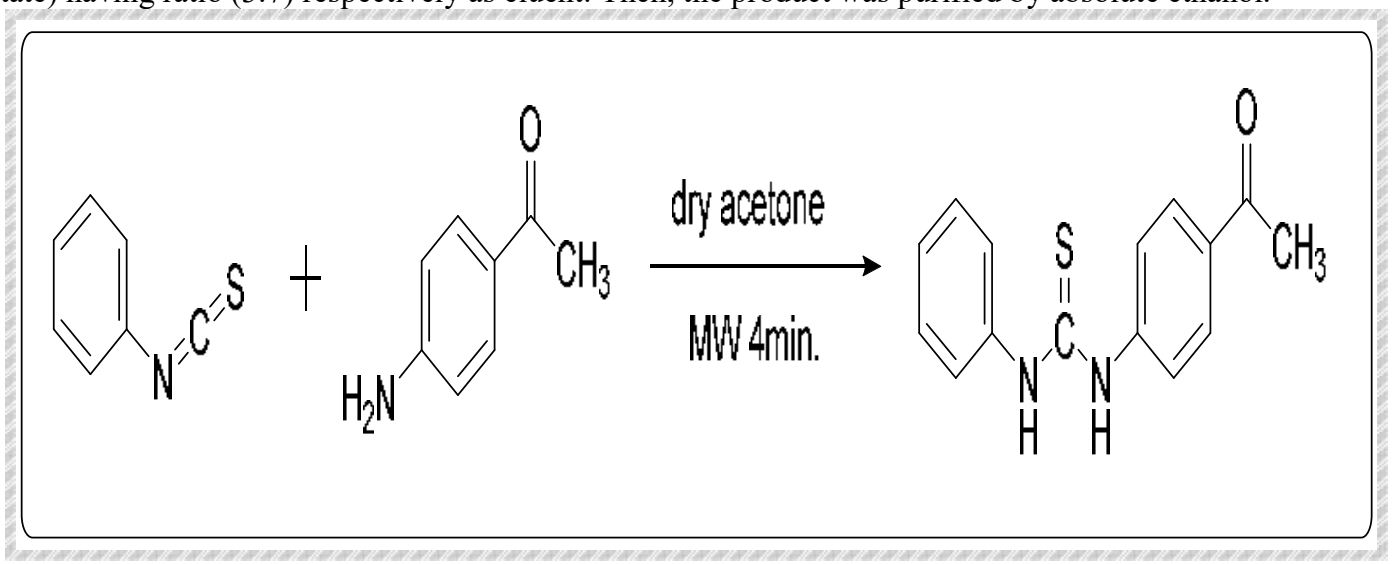

Scheme (1),

The mechanism of reaction can be explained in scheme (2), which first showed the formation of thiourea derivatives then nucleophilic attack of amine group of 4-amino acetophenone at the carbon atom of phenylisothiocyanate, the second nucleophilic attack of amine of thiourea toward active hydrogen of the other amine group.

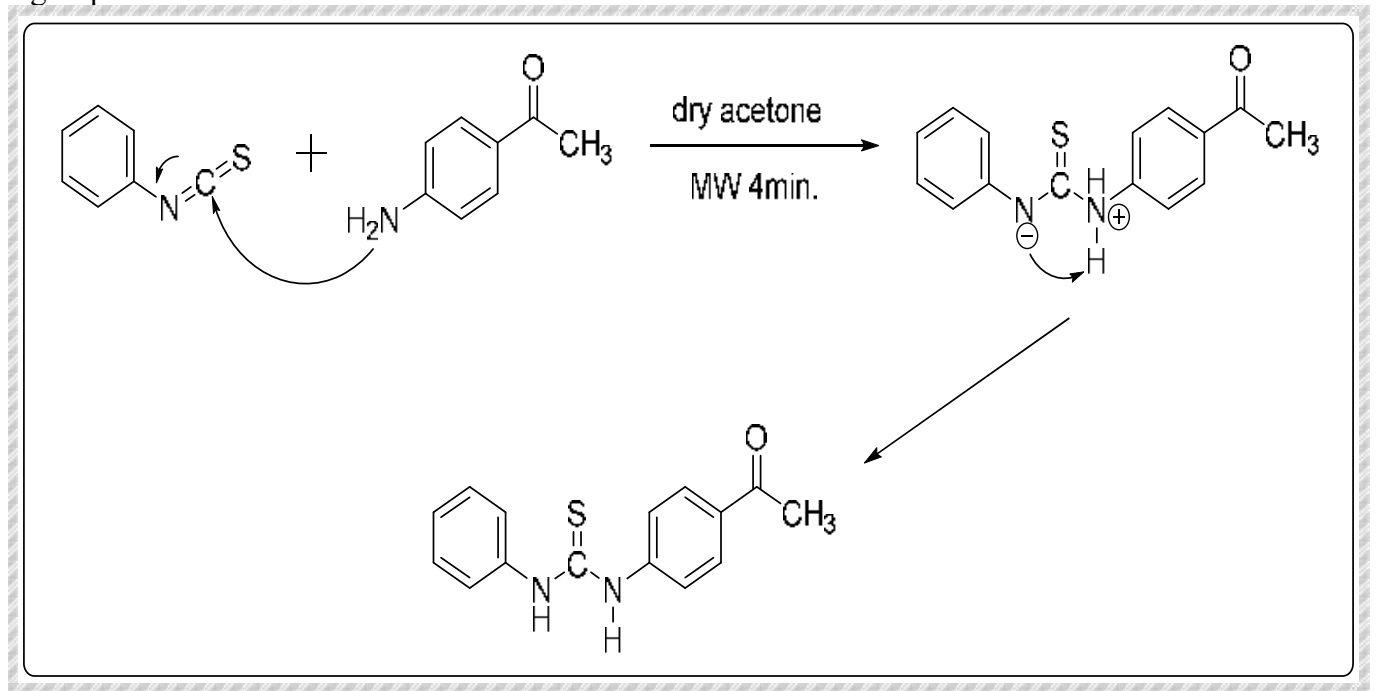

Scheme (2)

A series of chalcones were prepared according to Claisen Schmidt condensation [Claisen et al, 1881] and [Schmidt, 1881]. Variously substituted aromatic aldehydes with 1-(4-Acetylphenyl)-3-phenylthiourea by using base catalyzed, under microwave irradiation for (1-6) min. depending on substituent's of benzaldehyde to give corresponding chalcones. The reactions were monitored for their completion by TLC, shown in Scheme (3). 


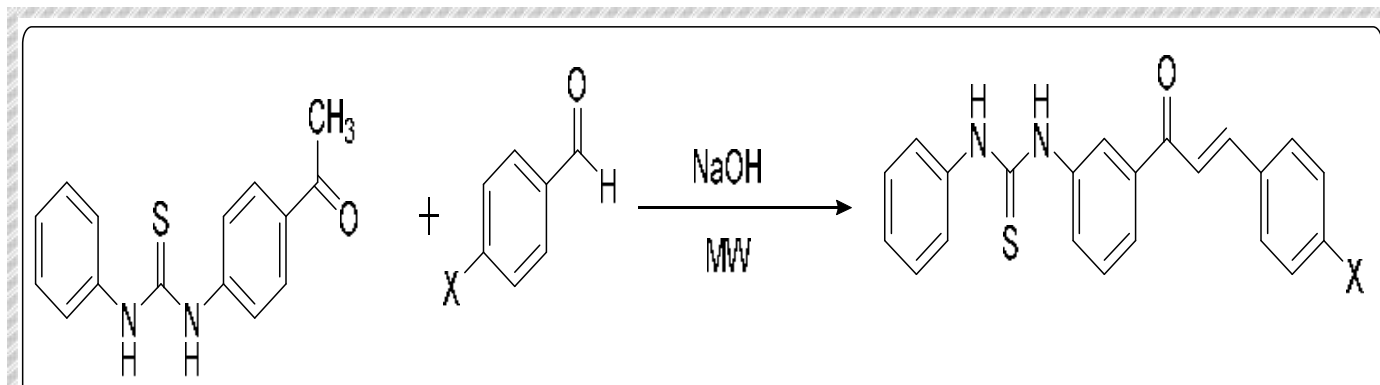

$\mathrm{X}=\mathrm{Br}: \mathrm{CH}_{3}, \mathrm{Ol}, \mathrm{FH}, \mathrm{N}\left(\mathrm{CH}_{3}\right)_{2}, \mathrm{NO}_{2}, \mathrm{OCH}_{3}, \mathrm{OH}, \mathrm{Van}$

Scheme (3)

The Synthesized chalcones showed different yield depending on the substituent groups, as they were electron with drawing group or electron donating group. Aldehydes with electron donating groups led to increase the electron density on the carbon atom of carbonyl group, results in enhancing their electronic properties and hence decreasing yield of products. In contrasting, those with electron withdrawing groups caused in increasing yield as the electron density on carbon atom of carbonyl were decreased as shown in scheme (4).

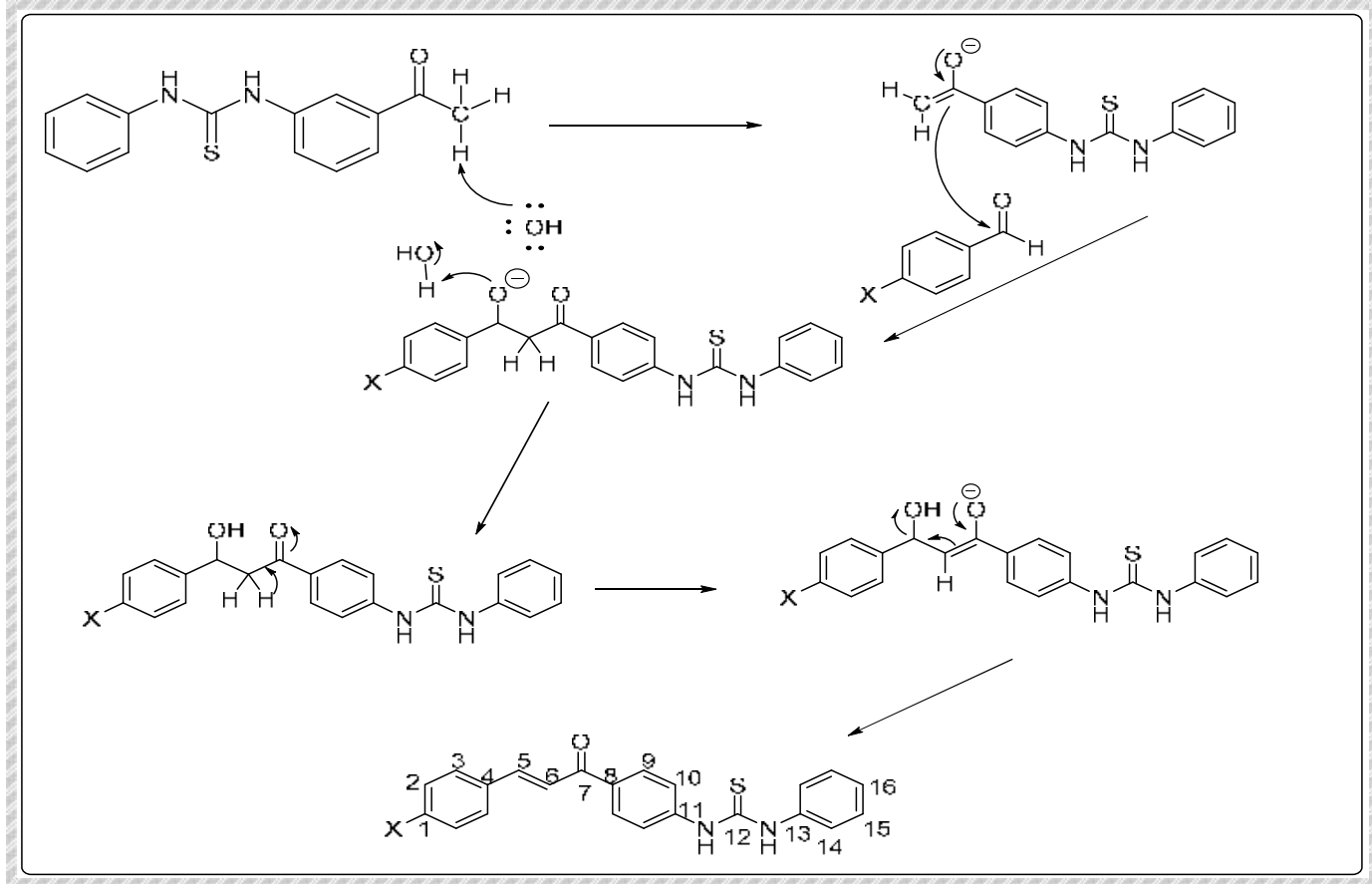

Scheme (4)

The structures of the synthesized compounds (a-j) were confirmed by their elemental analysis, IR, NMR and MS. CHN were situated within the range which confirmed the validity of the suggested structure of the prepared compounds. The purification compounds were tested by thin layer chromatography (TLC) using different eluents. The best separation was obtained in mixture of (benzene: methanol) (3:7) respectively as eluent. Then, the compounds were purified by using ethanol. The structures of synthesized compounds were determined on the basis of their FTIR [Al-Juburi, 2012], The spectra of all substituent chalcones compounds were characterized by the appearance of the absorption band that was attributed to the $(\mathrm{C}=\mathrm{O})$ stretching which appeared at $(1631-1681) \mathrm{cm}^{-}$ 1.

The infrared spectra of the synthesized substituent chalcones compounds in this study were measured. The IR spectra of these compounds showed a strong infrared absorption band in the region between $(3215-3375) \mathrm{cm}^{-1}$ due to $\mathrm{NH}$ stretching. Other strong bands appeared in the region (1546-1600) $\mathrm{cm}^{-1}$ which were characteristic of all chalcones compounds and were due to the $(\mathrm{C}=\mathrm{C})$ stretching. Also, medium absorption bands appeared between the region (1258-1338) $\mathrm{cm}^{-1}$ due to $(\mathrm{C}=\mathrm{S})$ stretching. Moreover, all these spectra showed medium absorption bands due to $(\mathrm{C}-\mathrm{H})$ aromatic stretching in the region $(3018-3112) \mathrm{cm}^{-1}$. However, the IR spectra of compounds $(\mathrm{b}, \mathrm{c}, \mathrm{d}$ 
and g) showed that weak absorption bands appeared in the region (2916-2978) $\mathrm{cm}^{-1}$ due to stretching of (-CH) and $\left(\mathrm{CH}_{3}\right)$ aliphatic group. While the compounds (i) and (j) showed that strong absorption bands appeared in the region (3448-3471) $\mathrm{cm}^{-1}$ due to stretching of $(-\mathrm{OH})$ group. Strong absorption bands appeared between the region (698$815) \mathrm{cm}^{-1}$ due to (C-X) stretching [Xue et al, 2009], [ Vanangamudi et al, 2011] and [Hayes et al,1968].

${ }^{1} \mathrm{HNMR}$ [Rudrapal et al, 2013, Al-Hazam, 2014]. The ${ }^{1} \mathrm{HNMR}$ spectra of (a-j) substituent chalconecompounds showed multiplet signal within the region (6.4-7.1) ppm due to aromatic ring system. Moreover, one proton of $(\mathrm{C}=\mathrm{CH})$ [Wade, 2006] which was interfere with the protons of aromatic ring. The second proton of $(\mathrm{C}=\mathrm{CH})$ at $(4.8-6.4) \mathrm{ppm}$.

All these spectra showed a peak at the region (8.7-9.9) ppm, which was due to the two-proton equivalent two secondary amino group [Yoon et al, 2014]. In addition, the ${ }^{1} \mathrm{HNMR}$ spectrum of $(\mathrm{b}, \mathrm{f}$ and $\mathrm{h}$ ) compounds showed singlet signals at the chemical shift (2.2-3.7) ppm due to the three and six proton equivalent of methoxy and methyl groups [Abood et al, 2013]. The low field singlet's at the region (7.6-8.9) ppm were assigned to hydroxyl group signal in the compounds ( $\mathrm{i}$ and $\mathrm{j}$ ).

The ${ }^{13} \mathrm{CNMR}$ [Kurtev, et al, 1985] and [Mehetre et al, 2018] spectra of substituent chalcone compounds showed (16-17) signal according to the carbon atoms exist in the structure, the signals in the region (93-165) ppm due to $\mathrm{C}_{1}, \mathrm{C}_{2}, \mathrm{C}_{3}, \mathrm{C}_{4}, \mathrm{C}_{8}, \mathrm{C}_{9}, \mathrm{C}_{10}, \mathrm{C}_{11}, \mathrm{C}_{13}, \mathrm{C}_{14}, \mathrm{C}_{15}$ and $\mathrm{C}_{16}$ for aromatic ring system including the compounds (aj). While the signals of double bond appearance in the region (129-146) ppm due to $\mathrm{C}_{5}$ and $\mathrm{C}_{6}$ for these compounds. Also $C_{7}$ and $C_{12}$ showed the signals in the region (137-165) and (161-180) come back to the $(C=O)$ and $(\mathrm{C}=\mathrm{S})$ respectively. In addition, the ${ }^{13} \mathrm{CNMR}$ spectrum of the compounds $(\mathrm{b}, \mathrm{f}$ and $\mathrm{h})$ showed signals at the chemical shift (23-61) ppm due to from the methyl, N-N-dimethyl and methoxy groups.

All synthesized substituent chalcone compounds had similar fragment mechanisms [Sande et al, 1972]. The suggested analysis mechanisms of (a-h) compound include seven steps; the first step was concerned with the formation of the fragment ion (2) and (3) by cleavage the bond between chalcone molecules and diphenylthiourea, the second step includes formation of the fragment ion (4) by losing fragment anilinium ion (7) which appeared at $(\mathrm{m} / \mathrm{z}=135)$ for all spectra. While the third step in the analysis mechanism includes the formation of the fragment ion (5) by losing carbonyl molecules which appeared at deferent $(\mathrm{m} / \mathrm{z})$ of these compounds. The fourth step includes formation of the fragment ion (6) by losing substituent groups atom for all compounds exception X10 carry out by two step, The fifth step includes formation of the fragment ion (8) by losing acetylene molecule atom which appeared at $(\mathrm{m} / \mathrm{z}=77)$ for all spectra. The final step include formation of the fragment ion (9) by losing acetylene molecule atom which appeared at $(\mathrm{m} / \mathrm{z}=51)$.

The mass spectra of ( $a$ and c) compounds showed an additional peak at $(\mathrm{m} / \mathrm{z}=438)$ and $(\mathrm{m} / \mathrm{z}=378)$, these peaks may be attributed to the molecular ion $[\mathrm{M}+2]$ which contains the second isotope bromine $\left(\mathrm{Br}^{81}\right)$ and $\left(\mathrm{Cl}^{37}\right)$ respectively.

The antibacterial [Al-Shamkhani and Al-Hazam, 2015] activities of the series [a-h] have been carried out against some strain of bacteria. The result [Table 1] showed that prepared compounds are toxic against the bacteria. The compounds (a-d) were found more active against the above microbes. The comparison of the antibacterial activity of these compounds with Streptomycin shows that these compounds have almost similar activity. The bacterial cultures for $S$. aurous and E. coli were obtained from Department of biology University of Basrah. Iraq. The bacterial cultures were incubated at $30^{\circ} \mathrm{C}$ for 24 hours by inoculation into nutrient agar. chalcones were stored dry at room temperature and dissolved $20 \mathrm{mg} / \mathrm{ml}$ in dimethyl sulfoxide [DMSO]. Antibacterial activities of each compound were evaluated by the agar disc-diffusion method. Mueller Hinton Agar Media $\left[15 \mathrm{~cm}^{3}\right] \mathrm{kept}$ at $45^{\circ} \mathrm{C}$ was poured in the petridishes and allowed to solidify. Poured Petri plates [9 $\mathrm{cm}]$ were incubated with $50 \mu \mathrm{L}$ of normal saline solution of above culture media [105-106 bacteria per ml]. Discs injected with prepared chalcones $[50 \mu \mathrm{L}]$ were applied on the solid agar medium by pressing tightly. The Petri plates were placed at $37^{\circ} \mathrm{C}$ for 24 hours. At the end of period, the inhibition zones formed on media were measured with a zone reader in millimeters. 
Table (1): Inhibition Zones (mm) of The Synthesis chalcone and Heterocyclic Compounds

\begin{tabular}{|c|c|c|}
\hline Code & $*$ E. Coli & $*$ S. aureus \\
\hline a & 8 & 13 \\
\hline $\mathrm{b}$ & 8 & 10 \\
\hline $\mathrm{c}$ & 10 & 10 \\
\hline $\mathrm{d}$ & zero & zero \\
\hline $\mathrm{e}$ & 10 & 12 \\
\hline $\mathrm{f}$ & 15 & 25 \\
\hline $\mathrm{g}$ & zero & 10 \\
\hline $\mathrm{h}$ & 15 & 20 \\
\hline $\mathrm{i}$ & 15 & 15 \\
\hline $\mathrm{j}$ & 30 & 30 \\
\hline Streptomycin & 9 & 9 \\
\hline
\end{tabular}

*Staphylococcus aureus, *Escherichia coli,

\section{Reference}

-A. Hoz de la, A. Dfaz, A. Moreno, "Microwaves in organic synthesis. Thermal and non-thermal microwave effects", Chem. Soc. Res; 2005, 34, 164.

-A. Chattree, I. R. Siddiqui, M. Abdul Waseem, "A Novel and Environmentally Benign synthesis of Imidazolidinone derivatives", Journal of Applicable Chemistry, 2013, 2, 171.

-R. N. Gedye, J. B. Wei, "A brief review: Microwave assisted organic reaction", Can. J. Chem.; 1998, $76,525$.

-M. Nuchter, B. Ondruschka, A. Jungnickel, U. Muller, "Organic processes initiated by non-classical energy sources", J. Phys. Org. Chem.; 2000, 13, 579.

-S. Syam, S. I. Abdelwahab, M. A. Al-Mamary, S. Mohan, Molecules 2012, 17, 6179.

-A. Modzelewska, C. Pettit, G. Achanta, N. E. Davidson, P. Huang, S. R. Khan, Bioorg. Med. Chem. 2006, 14, 3491.

-A. Hasan, L. Rasheed and A. Malik, "Synthesis and Characterization of Variably Halogenated Chalcones and Flavonols and Their Antifungal Activity", Asian J. Chem., 2007, 19, 929.

-F. Herenciaa, M. L. Ferrándiz, A. Ubeda, J. N. Domínguez, J. E.C. Gricela, M. Lobob and M. J. Alcaraza;(Synthesis and anti-inflammatory activity of chalcone derivatives) Bioorganic \& Medicinal Chemistry Letters, 1998,8,1169.

-M. R. Ahmad, V. G. Sastry, N. Bano and S. Anwar; (Synthesis of novel chalcone derivatives by conventional and microwave irradiation methods and their pharmacological activities), Arabian Journal of Chemistry, 2016, 9, 931.

-C. D. Tiellas, E. Grana, M. J. Reigosa and A. M. Sanchez-Moreiras; (Biological Activities and Novel Applications of chalcones) Planta Daninha,2016,34,3.

-M. Das and K. Manna;( Chalcone Scaffold in Anticancer Armamentarium: A Molecular Insight); J. Toxicol. 2016,1 .

-R. R. Kotha1, R. G. Kulkarni, A. K. Garige1, S. G. Nerella and A. Garlapati;( Synthesis and Cytotoxic Activity of New Chalcones and their Flavonol Derivatives); Med Chem (Los Angeles) 2017, 7:11

-M. Mellado, A. Madrid, M. Reyna, C. W. Oppenheimer, J. Mella, C. O. Salas, E. Sánchez and M. Cuellar;( synthesis of chalcones with antiproliferative activity on the SH-SY5Y neuroblastoma cell line: Quantitative Structure-Activity Relationship Models); Medicinal Chemistry Research,2018, 24, 2414.

-N. Yadav, S. K. Dixit, A. Bhattacharya, L. C. Mishra, M. Sharma, S. K. Awasthi and V. K. Bhasin (Antimalarial Activity of Newly Synthesized Chalcone Derivatives In Vitro); Chemical biology and drug design, 2012, 80, 340.

-X. Gan, Y. Wang and D. Hu,( Design, Synthesis, and Antiviral Activity of Novel Chalcone Derivatives Containing a Purine Moiety),Chinese J. of Chemistry,2017, 35, 665.

-H. A. Al-Hazam, Z. A. Al-Shamkani, N. A. Al-Masoudia, B. A. Saeed and C. Pannecouque (New chalcones and thiopyrimidine analogues derived from mefenamic acid: microwave-assisted synthesis, anti-HIV activity and cytotoxicity as antileukemic agents, z. Naturforschg. 2017.

-L. Claisen and A. Claparede; (Condensation von ketonen mit aldehyden); Ber. Dtsch. Chem. Ges., 1881, 14, 2460-2486.

-J. G. Schmidit; (Veter die einwirkung von aceton auf furfural und auf bittermandelol in grgenwart von alkalilauge); Ber. Datch. Chem. Ges., 1881, 14, 1459-1461.

-R. M. Al-Juburi, J. Al-Nahrain University, "Synthesis and Characterization of Some Heterocyclic Compounds (Oxazepine, Tetrazole) Derived from Schiff Bases", 2012, 15, 60. 
-Y. Xue and X. Gong; (The conformational, electronic and spectral properties of chalcones: A density functional theory study); J Mol. Struct. Theochem; 2009, 901, 226-231.

-G. Vanangamudi, M. Subramanian, P. Jayanthi, R. Arulkumaran, D. Kamalakkannan and G.Thirunarayanan;( IR and NMR spectral studies of some 2-hydroxy-1-naphthylchalcones: Assessment of substituent effects); Arab J. Chem., 2011, 7, 19.

-W.P. Hayes and C. J. Timmons; (The $\mathrm{C}=\mathrm{O}$ and $\mathrm{C}=\mathrm{C}$ fundamental and overtone stretching bands and the electronic absorption bands of some $\alpha, \beta$-unsaturated); Spectrochim Acta A 1968, 24 (4), 323-334.

-M. Rudrapal and B. De, "Chemistry and Biological Importance of Heterocyclic Schiff's Bases", Res. J. Pure \& App. Chem., 2013, 3, 232.

-H. A. Al-Hazam, A. A. Salih and A. F. Abbas," Synthesis, characterization and antibacterial study of 2 [(E)cimnnamoyl imino]4- methyl thiazole with some amino acids", Inter. J. Chem., \& App., 2014, 6, 7.

-L.G. Wade Jr.; (Organic Chemistry); 6th ed.; Pearson Prentice Hall, New York, NY, USA, 2006, 508-608

-H. Yoon, S. Eom, J. Hyun, G. Jo, D. Hwang, S. Lee, Y. Yong, J. C. Park, Y. H. Lee, and Y. Lim; $\left({ }^{1} \mathrm{H}\right.$ and $13 \mathrm{C}$ NMR Data on Hydroxy/methoxy Flavonoids and the Effects of Substituents on Chemical Shifts); Bull. Korean Chem. Soc. 2011, 32, (6), 2101-2104.

-N. Abood and J. A .AL-Hilfi ;( Theoretical NMR investigation of pyrazole and substituted Pyrazoles, DNMR and $1 \mathrm{H}$ spin-lattice relaxation times); The First Scientific Conference the Collage of Sciences, 2013, 340350.

-B. J. Kurtev, I. G. Pojarlleff and S. D. Sthlova; $\left({ }^{1} \mathrm{H}\right.$ and ${ }^{13} \mathrm{C}$ NMR syudy of the conformatioms of the atropisomers of some1-(11-naphthyl)-2,4-dioxo-(or 2-thio-4-oxo )-hexahydro-pyramibines); Journal of Molecular Structure, 1985, 128, 327-335.

-A. R. Mehetre1, S. R. Deshmukh and V. N. Bhosale; (Synthesis and Characterization of Schiff Base and Their Chalcone Derived from 3-Amino Acetophenone); International Journal for Research in Applied Science \& Engineering Technology, 2018, 6, (3), 2478-2481.

-V. de Sande C, J.W. Serum and M. Vandewalle; (Studies in organic Mass spectrometry-XII: Mass spectra of chalcones and flavanones. The isomerization of 2'-hydroxy-chalcone and flavanone); Org. Mass Spect.; 1972, $6,1333-1345$

-Z. A Naser Al-Shamkhani and H. A. Al-Hazam, "Microwave Assisted Synthesis, Characterizations and Antibacterial Activity of Some of Thiazole Derivatives", Res. J. of Pharm., Bio. and Chem., Sci., 2015, 6 , 719.

-Z. A Naser Al-Shamkhani and H. A. Al-Hazam, "Microwave Assisted Synthesis, Characterizations and Antibacterial Activity of Some of Thiazole Schiff base and azetidinone Derivatives", Chem., and Material Res., 2015, 7, 32. 